\title{
The protective effects of rutaecarpine on acute pancreatitis
}

\author{
LU YAN $^{1}$, QING-FU LI ${ }^{1}$, YAN-TING RONG ${ }^{1}$, YONG-HENG CHEN ${ }^{2}$, \\ ZHAO-HONG HUANG ${ }^{1}$, ZHI-ZHI WANG ${ }^{1}$ and JIE PENG ${ }^{1}$ \\ ${ }^{1}$ Department of Gastroenterology; ${ }^{2}$ Key Laboratory of Cancer Proteomics of Chinese Ministry of Health, \\ Xiangya Hospital, Central South University, Changsha, Hunan 410008, P.R. China
}

Received December 4, 2015; Accepted October 13, 2017

DOI: $10.3892 / \mathrm{ol} .2017 .7659$

\begin{abstract}
Acute pancreatitis (AP) is the acute inflammation of the pancreas. The morbidity of AP has increased in recent years. Certain patients eventually develop severe AP (SAP), which rapidly progresses to multiple organ dysfunction; the incidence of this occurring in patients with AP is $20-30 \%$. To date, no specific drugs or methods exist to treat this disease. Rutaecarpine relaxes vascular smooth muscle by stimulating calcitonin gene-related peptide (CGRP) release via activation of vanilloid receptor subtype 1 (VR1). It has been demonstrated that rutaecarpine induces a therapeutic effect on SAP. The present study was conducted to characterize the molecular mechanisms underlying the protective effects of rutaecarpine against AP using a rat model of AP. Gross pathological changes of the pancreas, as well as the pancreatic tissue histopathological score, were assessed following treatment with rutaecarpine, capsazepine or a combination of the two. Serum amylase activity was detected using an automatic biochemistry analyzer. Changes in the serum concentrations of interleukin (IL)-6, tumor necrosis factor (TNF- $\alpha$ ), IL-10 and CGRP were assessed by ELISA and radioimmunoassay. The results demonstrated that pre-treatment with rutaecarpine markedly decreased pancreatic inflammation and necrosis, reduced the volume of ascites, and significantly increased the plasma concentration of CGRP and the serum concentration of IL-10, an anti-inflammatory cytokine. However, serum concentrations of the inflammatory cytokines IL- 6 and TNF- $\alpha$ were decreased. The effect of rutaecarpine treatment markedly improved with increases in the drug dose. Capsazepine, as a competitive vanilloid receptor antagonist, abolished these protective effects of rutaecarpine against AP. Therefore, the results of the present study indicate
\end{abstract}

Correspondence to: Dr Jie Peng, Department of Gastroenterology, Xiangya Hospital, Central South University, 87 Xiangya Road, Changsha, Hunan 410008, P.R. China

E-mail: pengjie2014@csu.edu.cn

Abbreviations: AP, acute pancreatitis; Rut, rutaecarpine; CGRP, calcitonin gene-related peptide; Cap, capsazepine

Key words: rutaecarpine, acute pancreatitis, calcitonin gene-related peptide, capsazepine that rutaecarpine protects against $\mathrm{AP}$ in rats by upregulating endogenous CGRP release via activation VR1 of, to improving the microcirculation of the pancreatic tissue and regulate the expression of inflammatory factors.

\section{Introduction}

Acute pancreatitis (AP) is a severe disease that affects the abdomen and its incidence is increasing from 13 to $45 / 100,000(1,2)$. In the majority of cases, AP is a mild and self-limiting disease; however, $30 \%$ of patients will develop severe acute pancreatitis (SAP), which is characterized by severe attacks, including pancreatic necrosis, intestinal barrier dysfunction and bacterial translocation, leading to multiple organ dysfunction (mortality rate, 15-30\%) (3-5). Currently, the mechanisms involved in the pathogenesis of AP and associated pancreatic injury have not been fully elucidated. Among the various hypotheses used to explain the development of AP, microcirculatory disturbance and inflammatory mediation have attracted the most attention (6). Pancreatic microcirculatory disorders may be important pathogenic factors in determining acute pancreatitis (7) and it has been suggested that a number of factors are involved in the development of pancreatic microcirculatory disturbance (8). A number of pro-inflammatory cytokines may be released from damaged pancreatic tissue (9). These cytokines may cause multiple organ injury by instigating and aggravating microcirculatory disturbances (6). Current pharmaceutical therapies used to treat AP focuses on reducing pancreatic secretion and secondary injury (including fasting, protease inhibitors, antibiotics and fluid resuscitation). Due to unpredictable side effects and poor patient compliance, these therapies have a limited impact on the incidence and severity of AP (10). Therefore, a more in-depth understanding of the underlying molecular mechanisms, and the development of novel treatment strategies are required for AP.

Rutaecarpine (Fig. 1) is a quinazolinocarboline alkaloid isolated from $\mathrm{Wu}-\mathrm{Chu}-\mathrm{Yu}$, the dried fruit of Evodia rutaecarpa Bentham (Rutaceae), a Chinese herbal drug (11). Rutaecarpine possesses a number of biological properties, including anti-hypertension, anti-thrombotic, anticancer and anti-inflammatory activities, particularly on relaxing vascular smooth muscle $(12,13)$. Previous studies have revealed that the multiple pharmacological effects elicited by rutaecarpine are driven by the increase in endogenous calcitonin gene-related 
peptide (CGRP) release following the activation of vanilloid receptor subtype 1 (VR1) $(11,14)$. VR1, also known as the capsaicin receptor, is primarily expressed in sensory nerves. Primary sensory nerves sensitive to capsaicin are extensively distributed among different tissues and organs, and serve an important function in regulating peripheral vascular resistance (15). The activation of VR1 leads to the release of multiple neurotransmitters, including substance $\mathrm{P}(\mathrm{SP})$ and CGRP (16). Sensory nerves are important in limiting the development of AP and the stimulation of sensory nerves. Furthermore, the administration of CGRP may protect against pancreatic injury (17-19). Additionally, CGRP is a competitive VR antagonist, and therefore may be able to abolish the effects of VR (20).

It has been previously demonstrated that rutaecarpine has a therapeutic effect on SAP (21). However, to the best of our knowledge, the mechanism(s) responsible for the action of rutaecarpine in AP has not yet been reported. Previous studies performed in rats have indicated that the effects of rutaecarpine on gastroprotection and vasodilation may be due to the increase in endogenous CGRP release following VR1 activation $(11,22)$. CGRP immunoreactivity has been detected in nerve fibers innervating the pancreas (23). Therefore, the present study investigated the protective effects of rutaecarpine on AP in rats and examined whether the functional mechanisms of rutaecarpine are associated with an increase in endogenous CGRP release following the activation of VR1.

\section{Materials and methods}

Animals. A total of 100 male Sprague-Dawley (SD) rats (Laboratory Animal Center, Xiangya Hospital, Central South University, China), weighing $250 \pm 50 \mathrm{~g}$, were used in the present study. All animals were housed in a controlled temperature environment $\left(25^{\circ} \mathrm{C} ; 50 \%\right.$ humidity $)$ with a 12 -hour day/night rhythm with free access to standard laboratory chow and water. All animals received humane care in compliance with the National Institutes of Health standards (Guide for the Care and Use of Laboratory Animals, revised 1996) (24). The present study was approved by the Ethics Committee of the Xiangya School of Medicine, Central South University (Changsha, China).

Reagents. Rutaecarpine (purity, $>98 \%$ ) was purchased from Shanghai Yuanye Biotechnology Co., Ltd. (Shanghai, China). Capsazepine (a competitive VR antagonist) (purity, >98\%) and $45 \%$ sodium taurocholate were purchased from Sigma-Aldrich (Merck KGaA, Darmstadt, Germany). Dimethyl sulfoxide and ethanol were mixed at a ratio of $1: 4$ and used to dissolve rutaecarpine. A vehicle containing $8 \%$ ethanol, $2 \%$ dimethyl sulfoxide and $90 \%$ saline was used to dissolve capsazepine.

Modeling and grouping of animals. SD rats were randomly divided into 10 different groups (all $\mathrm{n}=10$ ). The groups included were as follows: i) Sham-operated group (Sham), AP was not induced during surgery; ii) AP group (AP), 5\% sodium taurocholate solution $(1.0 \mathrm{ml} / \mathrm{kg})$ was injected into rats to induce AP during surgery; iii) Sham-operated + rutaecarpine $(100 \mu \mathrm{g} / \mathrm{kg})$ group (Sham+Rut), rats were injected with $100 \mu \mathrm{g} / \mathrm{kg}$ rutaecarpine into the sublingual vein 20 min prior to surgery, during which AP was not induced; iv) $\mathrm{AP}+$ rutaecarpine $(30 \mu \mathrm{g} / \mathrm{kg})$ group $(\mathrm{AP}+\mathrm{Rut} \mathrm{L})$, rats received an injection of $30 \mu \mathrm{g} / \mathrm{kg}$ rutaecarpine into the sublingual vein 20 min prior to surgery, in which AP was induced; v) AP + rutaecarpine $(100 \mu \mathrm{g} / \mathrm{kg})$ group (AP+Rut $\mathrm{M})$, rats were injected with $100 \mu \mathrm{g} / \mathrm{kg}$ rutaecarpine into the sublingual vein 20 min prior to surgery, in which AP was induced; vi) AP + rutaecarpine $(300 \mu \mathrm{g} / \mathrm{kg})$ group $(\mathrm{AP}+\mathrm{Rut} \mathrm{H})$, rats were injected with $300 \mu \mathrm{g} / \mathrm{kg}$ rutaecarpine into the sublingual vein 20 min prior to surgery, in which AP was induced; vii) sham-operated + capsazepine group (Sham+Cap), animals were injected with $3 \mathrm{mg} / \mathrm{kg}$ capsazepine into the sublingual vein 30 min prior to surgery, in which AP was not induced; viii) AP + capsazepine group (AP+Cap), animals were injected with $3 \mathrm{mg} / \mathrm{kg}$ capsazepine into the sublingual vein 30 min prior to surgery; ix) AP + capsazepine + rutaecarpine $(100 \mu \mathrm{g} / \mathrm{kg})$ group $(\mathrm{AP}+\mathrm{Cap}+\mathrm{Rut})$, mice were injected with $3 \mathrm{mg} / \mathrm{kg}$ capsazepine into the sublingual vein $30 \mathrm{~min}$ prior to surgery and were subsequently injected with $100 \mu \mathrm{g} / \mathrm{kg}$ rutaecarpine into the sublingual vein $20 \mathrm{~min}$ prior to surgery, in which AP was induced; and $\mathrm{x}$ ) vehicle control group (AP+Sol), mice were injected with the vehicle [a mixture of dimethyl sulfoxide and ethanol (1:4) in a volume of $0.125 \mathrm{ml} / \mathrm{kg}$ ] into the sublingual vein 20 min prior to surgery, in which AP was induced.

$\mathrm{SD}$ rats were fasted for $12 \mathrm{~h}$ prior to surgery. Subsequently, rats were administered $3 \%$ pentobarbital sodium $(40 \mathrm{mg} / \mathrm{kg}$; Sigma-Aldrich; Merck KGaA) intraperitoneally to induce anesthesia. Following a conventional disinfection (first with $2.5 \%$ iodine inunction, followed by drying with $70 \%$ alcohol twice) and towel spreading, an incision $(\sim 1.5 \mathrm{~cm})$ along the white line of abdomen was created. Freshly prepared 5\% sodium taurocholate solution was used to induce AP by retrograde infusion through the cholangiopancreatic duct following laparotomy (25). Instead of 5\% sodium taurocholate solution, an equivalent volume of normal saline solution was administered to the Sham group. The incision was closed with a continuous silk suture. All rats were sacrificed $24 \mathrm{~h}$ after surgery and arterial blood and pancreatic tissue were collected. The serum was collected following centrifugation $\left(4^{\circ} \mathrm{C}, 1,500 \mathrm{x} \mathrm{g}\right.$ for $\left.5 \mathrm{~min}\right)$ and stored at $-20^{\circ} \mathrm{C}$. Pancreatic tissue was fixed in $4 \%$ phosphate-buffered formaldehyde at $4^{\circ} \mathrm{C}$ prior to histopathological examination.

Detection of ascite volume. The abdomen was opened following euthanasia of the rats (all rats were sacrificed $24 \mathrm{~h}$ after surgery), ascites were removed from the abdominal cavity using a syringe and a measuring cylinder was used to measure the volume of the ascites.

Histopathology. Formaldehyde-fixed pancreatic tissues obtained from the rats were embedded in paraffin, sectioned at $4 \mu \mathrm{m}$ thick, and were dewaxed in xylene, rehydrated through decreasing concentrations of ethanol and then washed in PBS. Sections were stained with hematoxylin (4 min), washed with $\mathrm{H}_{2} \mathrm{O}$, and then $0.5 \%$ eosin $(1 \mathrm{~min})$ at room temperature. Two independent pathologists, who were blinded to this experiment, evaluated the sections under a light microscope. As outlined by the histopathological features scoring criteria (26), 
the severity of pancreatitis was scored according to edema, vacuolization, necrosis and inflammation.

Measurement of serum amylase activity. Serum amylase activity was measured using a Hitachi 7170A full-automatic biochemical analyzer (Hitachi, Ltd., Tokyo, Japan) according to the manufacturer's protocol ( $\alpha$-Amy-DR; Autec Diagnostics, Bötzingen, Germany).

Cytokines assay. ELISA was performed to measure the serum concentrations of interleukin (IL)-6 (Rat IL-6 ELISA kit; cat. no. JER-04), IL-10 (Rat IL-10 ELISA kit; cat. no. JER-05) and tumor necrosis factor (TNF)- $\alpha$ (Rat TNF- $\alpha$ ELISA kit; cat. no. JER-06), according to the manufacturer's protocol (all products were purchased from Joyee Biotechnics Co., Ltd., Shanghai, China). Absorbance values were used to determine cytokine concentrations using a standard curve. All samples were tested three times.

Measurement of plasma CGRP concentration. Plasma was collected when rats were sacrificed $24 \mathrm{~h}$ after surgery by centrifugation at $1,000 \mathrm{x} \mathrm{g}$ for $30 \mathrm{~min}$ at $4^{\circ} \mathrm{C}$. Subsequently, CGRP concentration in plasma was measured using a radioimmunoassay kit, according to the manufacturer's protocols.

Statistical analysis. All results are presented as the mean \pm standard deviation and were analyzed using SPSS software (version 17.0; SPSS, Inc., Chicago, IL, USA). Results were compared between all groups using one-way analysis of variance and least significant difference $t$ tests were used to compare two different groups. $\mathrm{P}<0.05$ was considered to indicate a statistically significant difference.

\section{Results}

Pathological changes of the pancreas. To investigate the protective role of rutaecarpine in a rat model of AP, histopathological changes of the pancreas in rats from each group were assessed by evaluating H\&E-stained tissue. Representative histological sections are presented in Fig. 2. There were no evident histopathological changes identified in the pancreas of mice from the Sham, Sham+Rut and Sham+Cap groups (Fig. 2A, C and G); however, the interlobular septum was slightly broadened in Sham+Rut group. There were varied degrees of pathological changes in the pancreatic acinar, including acute inflammation, necrosis, dilated intercellular spaces and interlobular septum in the other groups (Fig. 2B, D-F and H-J). Conspicuous hemorrhagic necrosis, pancreatic edema, interstitial leukocyte and erythrocyte infiltration, and acinar cell vacuolization were observed in the AP and AP+Sol groups (Fig. 2B and J). Compared with the AP group, the extent and severity of pancreatic injuries were markedly alleviated in the AP+Rut L, AP+Rut M and AP+Rut $\mathrm{H}$ groups (Fig. 2D-F and K). Rutaecarpine (30, 100 and $300 \mu \mathrm{g} / \mathrm{kg}$ ) significantly decreased the severity of pathological changes in a dose-dependent manner (Fig. 2D-F and K). As presented in Fig. $2 \mathrm{~K}$, pancreatic histological scores were highest in the AP+Cap and AP+Cap+Rut groups; they were even significantly higher than in the AP group $(\mathrm{P}<0.05)$. Coagulative necrosis was observed in these two groups, which

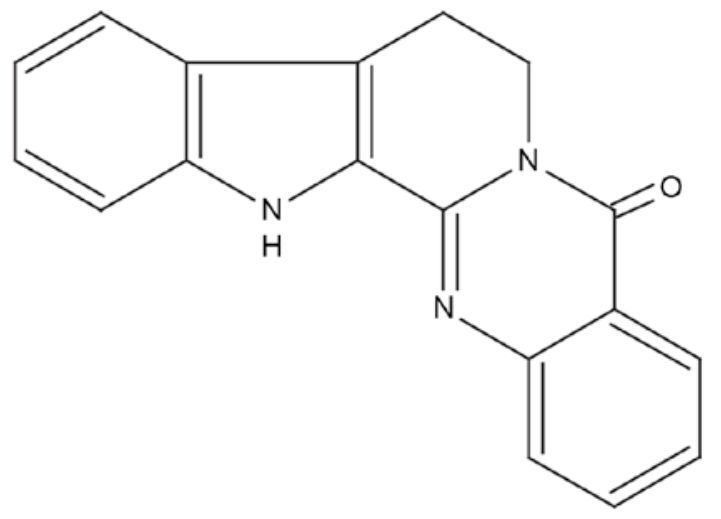

Figure 1. Chemical structure of rutaecarpine.

also exhibited widened interlobular septums and the disappearance of acinic structures (Fig. 2H and I).

Changes in the volume of ascites and serum amylase activity. In the Sham, Sham+Rut and Sham+Cap groups, ascite volume in the abdominal cavity of rats was low and barely detectable (Fig. 3) and serum amylase activity remained low in these 3 groups (Fig. 4). Ascite volume significantly increased in the AP and AP+Sol groups $(\mathrm{P}<0.05$; Fig. 3). Furthermore, compared with the Sham groups, the AP groups exhibited markedly increased levels of serum amylase $(\mathrm{P}<0.05$; Fig. 4). However, pre-treatment with 30,100 and $300 \mu \mathrm{g} / \mathrm{kg}$ rutaecarpine significantly reduced the volume of ascites and serum amylase activity in a dose-dependent manner $(\mathrm{P}<0.05)$. Capsazepine, a competitive VR1 antagonist reversed these effects (Figs. 3 and 4).

Changes in inflammatory cytokines. Cytokines serve an important function in the systemic response in AP; therefore, changes in the levels of IL-10, IL-6 and TNF- $\alpha$ were assessed in the serum of the rats to identify the mechanism by which rutaecarpine protects against rutaecarpine in AP. Groups in which AP was induced by injection of 5\% sodium taurocholate exhibited a marked increase of IL- 6 and TNF- $\alpha$ serum concentrations (Fig. 5). IL-6 and TNF- $\alpha$ are two pro-inflammatory cytokines expressed in response to local damage to the pancreas. Pre-treatment with 30, 100 and $300 \mu \mathrm{g} / \mathrm{kg}$ rutaecarpine significantly reduced IL- 6 and TNF- $\alpha$ levels compared with the AP group in a dose-dependent manner $(\mathrm{P}<0.05$; Fig. 5). Furthermore, pre-treatment with rutaecarpine significantly increased serum concentrations of IL-10 (P<0.05; Fig. 6), an anti-inflammatory cytokine that may attenuate pancreatic damage (27). However, rats injected with capsazepine prior to surgery exhibited significantly higher IL-6 and TNF- $\alpha$ concentrations $(\mathrm{P}<0.05)$ and significantly lower serum IL-10 concentrations $(\mathrm{P}<0.05)$ compared with those treated with rutaecarpine. This indicates that rutaecarpine suppresses the inflammatory response in AP, an effect that is reversed by capsazepine.

CGRP concentration in plasma. Pre-treatment with 30, 100 or $300 \mu \mathrm{g} / \mathrm{kg}$ rutaecarpine significantly upregulated CGRP concentrations in a dose-dependent manner $(\mathrm{P}<0.05$; Fig. 7$)$. Contrastingly, treatment with capsazepine led to a significant 

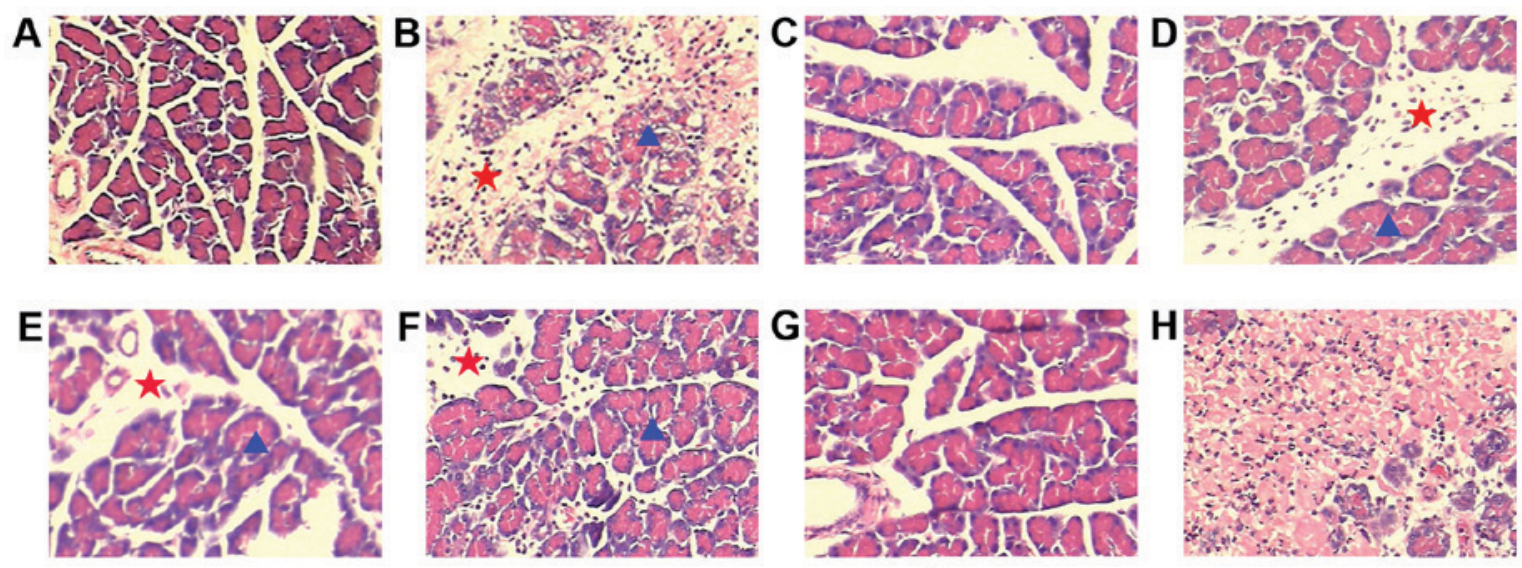

\section{G.}
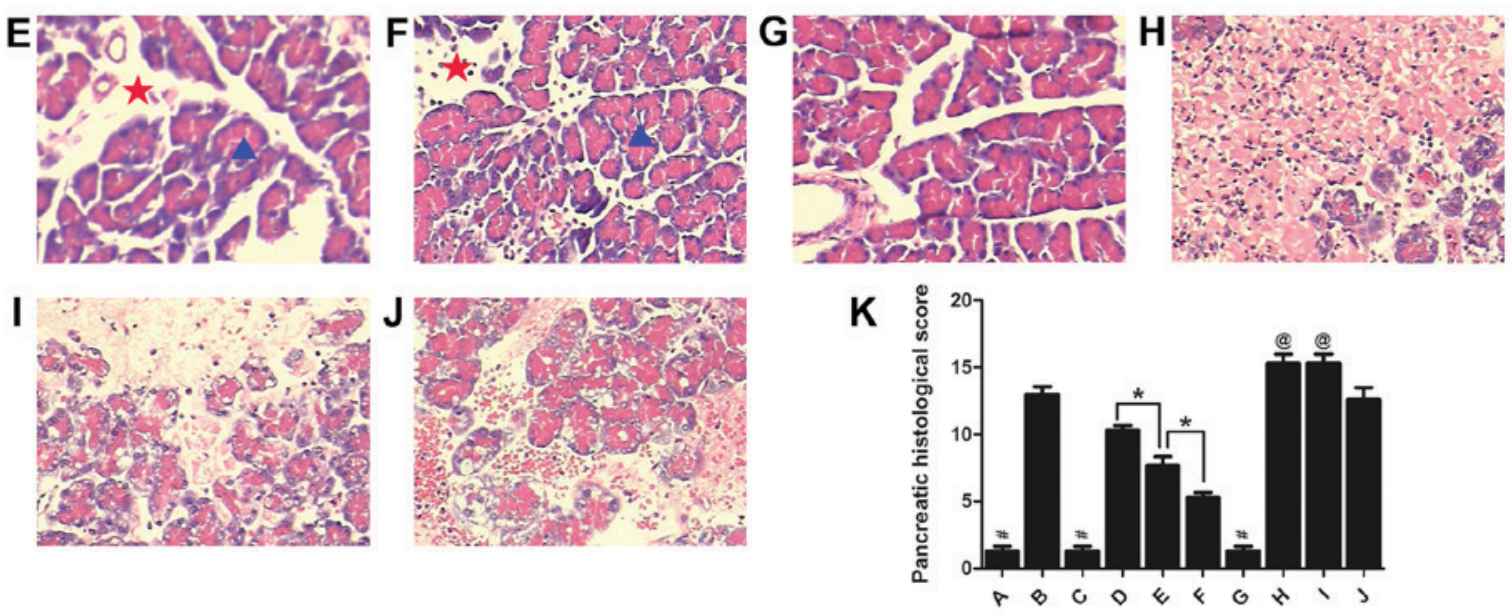

Figure 2. Morphological changes in the pancreas and the pancreatic histological scores in each group $(\mathrm{n}=10)$. Stained sections from the (A) Sham, (B) AP, (C) Sham+Rut (100 $\mu \mathrm{g} / \mathrm{kg})$, (D) AP+Rut L (30 $\mu \mathrm{g} / \mathrm{kg})$, (E) AP+Rut M (100 $\mu \mathrm{g} / \mathrm{kg}),(\mathrm{F}) \mathrm{AP}+\mathrm{Rut} \mathrm{H}(300 \mu \mathrm{g} / \mathrm{kg})$, (G) Sham+Cap, (H) AP+Cap, (I) AP+Cap+Rut $(100 \mu \mathrm{g} / \mathrm{kg})$ and $(\mathrm{J}) \mathrm{AP}+$ Sol groups. Magnification, x200. (K) Quantification of histological scores of the different groups. Results are presented as the mean \pm standard deviation. Pancreatic acinar are indicated with a blue triangle and the interlobular septum is indicated with a red star. Conspicuous hemorrhagic necrosis, pancreatic edema, interstitial leukocyte and erythrocyte infiltration and acinar cell vacuolization were demonstrated in the AP only group. However, pancreatic injuries were markedly alleviated in the AP+Rut groups. Magnification, $\mathrm{x} 200 .{ }^{*} \mathrm{P}<0.05 ;{ }^{*} \mathrm{P}<0.05$ vs. (B), (D-F) and (H-J); ${ }^{\circledR} \mathrm{P}<0.05$ vs. (A-G) and (J); AP, acute pancreatitis; Rut, rutaecarpine; Cap, capsazepine.

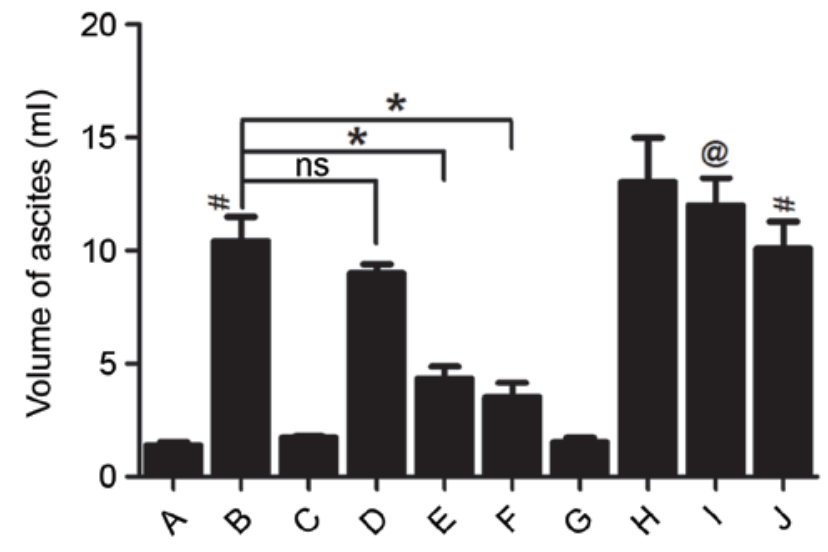

Figure 3. Changes in the volume of ascites. (A) Sham; (B) AP; (C) Sham+Rut $(100 \mu \mathrm{g} / \mathrm{kg})$; (D) AP+Rut L (30 $\mu \mathrm{g} / \mathrm{kg})$; (E) AP+Rut M $(100 \mu \mathrm{g} / \mathrm{kg})$; (F) AP+Rut H (300 $\mu \mathrm{g} / \mathrm{kg})$; (G) Sham+Cap; (H) AP+Cap; (I) AP+Cap+Rut $(100 \mu \mathrm{g} / \mathrm{kg}) ;(\mathrm{J}) \mathrm{AP}+$ Sol. Results are presented as the mean \pm standard deviation. ( $\mathrm{n}=10) .{ }^{\prime \prime} \mathrm{P}<0.05$ vs. (A), (C) and $(\mathrm{G}) ;{ }^{\circledR} \mathrm{P}<0.05$ vs. (E); ${ }^{*} \mathrm{P}<0.05$. AP, acute pancreatitis; Rut, rutaecarpine; Cap, capsazepine; ns, not significant.

decrease in plasma CGRP levels even when rutaecarpine was administered $(\mathrm{P}<0.05$; Fig. 7). Taken together, these results indicate that capsazepine may attenuate the effect of rutaecarpine on CGRP concentration.

\section{Discussion}

The morbidity of patients with acute pancreatitis has increased in recent years. However, the pharmacological therapies

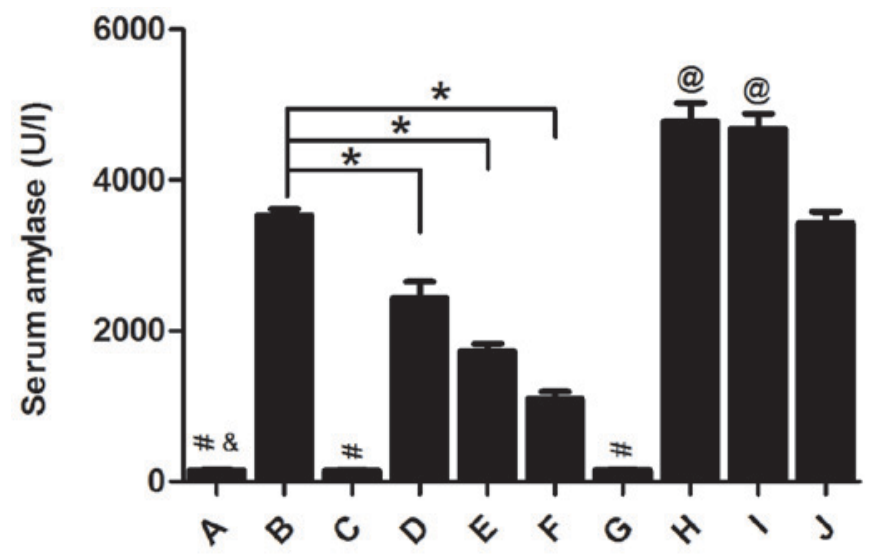

Figure 4. Serum concentration of amylase. (A) Sham; (B) AP; (C) Sham+Rut $(100 \mu \mathrm{g} / \mathrm{kg}) ;$ (D) AP+Rut L $(30 \mu \mathrm{g} / \mathrm{kg}) ;(\mathrm{E}) \mathrm{AP}+\operatorname{Rut~M}(100 \mu \mathrm{g} / \mathrm{kg}) ;(\mathrm{F}) \mathrm{AP}+\mathrm{RutH}$ (300 $\mu \mathrm{g} / \mathrm{kg})$; (G) Sham+Cap; (H) AP+Cap; (I) AP+Cap+Rut (100 $\mu \mathrm{g} / \mathrm{kg})$; (J) AP+Sol. Results are presented as the mean \pm standard deviation. $(n=10)$. ${ }^{\#} \mathrm{P}<0.05$ vs. (B), (D-F) and (H-J); ${ }^{\circledR} \mathrm{P}<0.05$ vs. (B); ${ }^{\circledR} \mathrm{P}<0.05$ vs. (A-G) and (J); ${ }^{*} \mathrm{P}<0.05$. AP, acute pancreatitis; Rut, rutaecarpine; Cap, capsazepine.

currently used to treat AP are limited. Therefore, a more in-depth understanding of the pathogenic mechanisms of AP and the identification of novel treatment strategies to treat it, are urgently required. Microcirculatory disorders serve an important function in the pathogenesis of AP, as they cause hypoxic damage in focal tissue and eventually induce edema formation and necrosis (28). A variety of pro-inflammatory cytokines are released by injured pancreas tissue (9). These inflammatory mediators are involved in the entire AP process, 

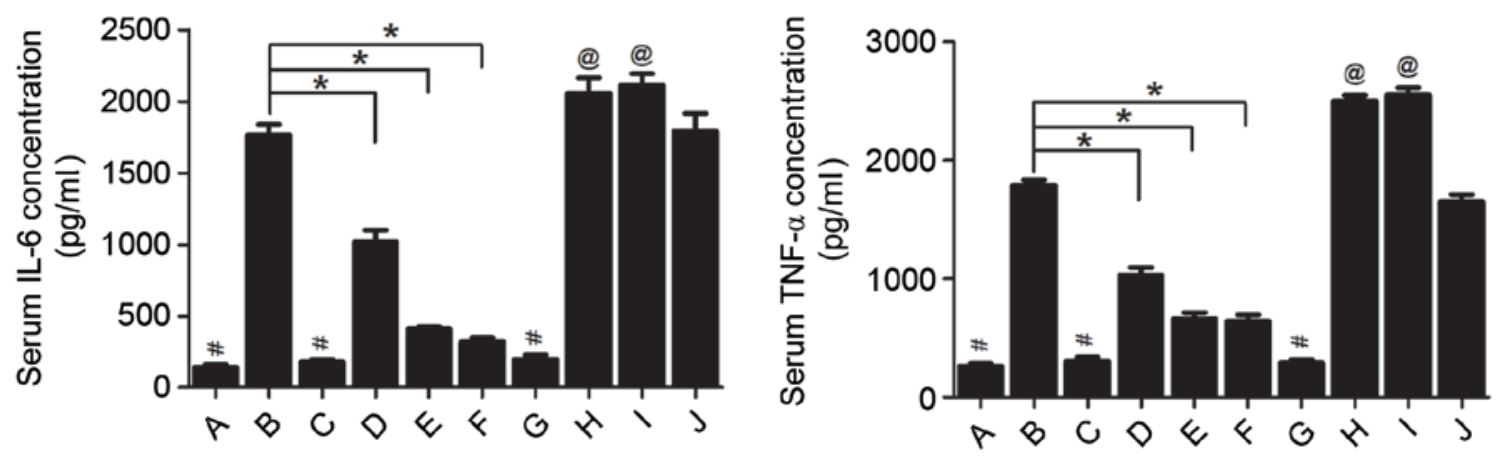

Figure 5. Serum concentrations of IL-6 and TNF- $\alpha$. (A) Sham; (B) AP; (C) Sham+Rut (100 $\mu \mathrm{g} / \mathrm{kg}$ ); (D) AP+Rut L (30 $\mu \mathrm{g} / \mathrm{kg}) ;(\mathrm{E}) \mathrm{AP}+\mathrm{Rut} \mathrm{M}$ (100 $\mu \mathrm{g} / \mathrm{kg}$ ); (F) AP+Rut H (300 $\mu \mathrm{g} / \mathrm{kg})$; (G) Sham+Cap; (H) AP+Cap; (I) AP+Cap+Rut (100 $\mu \mathrm{g} / \mathrm{kg})$; (J) AP+Sol. Results are presented as the mean \pm standard deviation. (n=10). ${ }^{~} \mathrm{P}<0.05$ vs. (B), (D-F) and (H-J); ${ }^{\circledR} \mathrm{P}<0.05$ vs.(B); " $\mathrm{P}<0.05$. IL-6, interleukin-6; TNF- $\alpha$, tumor necrosis factor- $\alpha$; AP, acute pancreatitis; Rut, rutaecarpine; Cap, capsazepine.

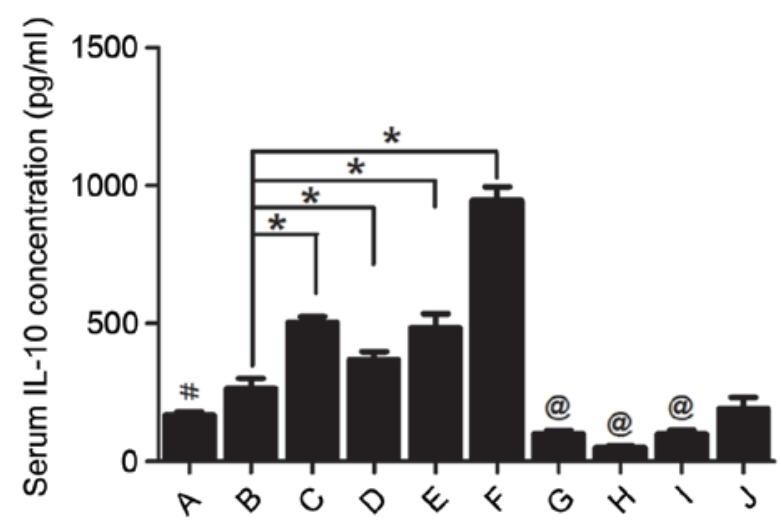

Figure 6. Serum concentration of IL-10. (A) Sham; (B) AP; (C) Sham+Rut $(100 \mu \mathrm{g} / \mathrm{kg})$; (D) AP+Rut L $(30 \mu \mathrm{g} / \mathrm{kg})$; (E) AP+Rut M $(100 \mu \mathrm{g} / \mathrm{kg})$; (F) AP+Rut H (300 $\mu \mathrm{g} / \mathrm{kg})$; (G) Sham+Cap; (H) AP+Cap; (I) AP+Cap+Rut $(100 \mu \mathrm{g} / \mathrm{kg})$; (J) AP+Sol. Results are presented as the mean \pm standard deviation. (n=10). ${ }^{\#} \mathrm{P}<0.05$ vs. (B); ${ }^{\circledR} \mathrm{P}<0.05$ vs. (E); ${ }^{*} \mathrm{P}<0.05$. IL-10, interleukin-10; AP, acute pancreatitis; Rut, rutaecarpine; Cap, capsazepine.

triggering and aggravating the microcirculatory disorders, which leads to injuries in multiple organs (28).

Rutaecarpine is a vasodilator that modulates peripheral vascular resistance and may be associated with the upregulation of endogenous CGRP release via activation of VR1 $(15,29)$. VR1 is almost exclusively distributed in the primary sensory neurons (30). Various vasodilator neuropeptides, including CGRP, are released by sensory afferent fibers. CGRP regulates regional organ blood flow and vascular tone, and is a potent vasodilator (31). The mammalian pancreas is richly innervated by a number of different nerve fibers and CGRP immunoreactivity has been observed in these nerve fibers (23). Previous studies have demonstrated that sensory nerves limit the development of AP and that stimulation of sensory nerves or administration of CGRP may protect against pancreatic injury (17-19). It has been demonstrated that rutaecarpine has a therapeutic effect on SAP (21). However, to the best of our knowledge, the mechanism of rutaecarpine action in AP has not yet been described. The results of the present study indicate that pre-treatment with rutaecarpine alleviates pancreatic inflammation and necrosis in a rat model of pancreatitis, reducing the volume of ascites and serum amylase activity, whilst significantly increasing CGRP plasma concentration.

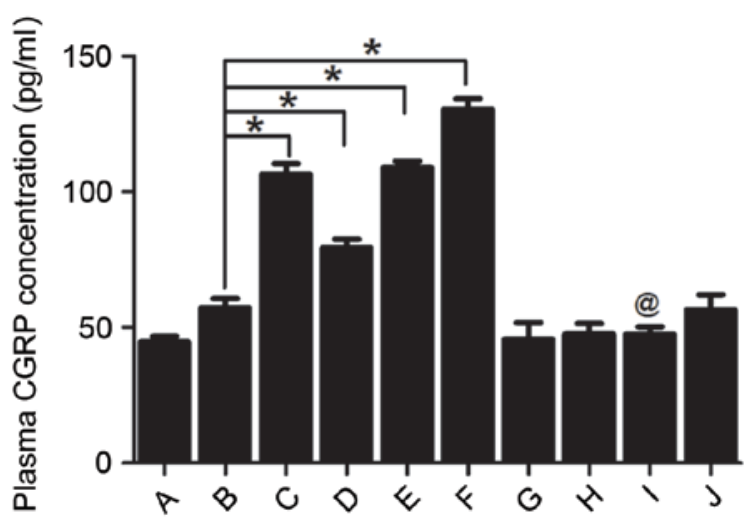

Figure 7. Plasma CGRP concentrations. (A) Sham; (B) AP; (C) Sham+Rut $(100 \mu \mathrm{g} / \mathrm{kg}) ;$ (D) AP+Rut L $(30 \mu \mathrm{g} / \mathrm{kg})$; (E) AP+Rut M $(100 \mu \mathrm{g} / \mathrm{kg}) ;(\mathrm{F}) \mathrm{AP}+\mathrm{Rut}$ $\mathrm{H}(300 \mu \mathrm{g} / \mathrm{kg})$; (G) Sham+Cap; (H) AP+Cap; (I) AP+Cap+Rut (100 $\mu \mathrm{g} / \mathrm{kg})$; (J) AP+Sol. ${ }^{\circledR} \mathrm{P}<0.05$ vs. (E); $\mathrm{P}<0.05$. CGRP, calcitonin gene-related peptide; AP, acute pancreatitis; Rut, rutaecarpine; Cap, capsazepine.

The effect of rutaecarpine treatment increased as the drug dose increased; however, its protective effects were attenuated by capsazepine. These results indicated that the protective effect of rutaecarpine against AP is mediated by upregulating endogenous CGRP release via the activation of VR1.

Inflammatory mediators are key players in the systemic response to AP (9) and induce and aggravate microcirculatory disturbance throughout the body (28). Local damage of the pancreas is accompanied by the presence of leukocytes that release various pro-inflammatory cytokines, including TNF- $\alpha$, IL- 6 and IL-1 $\beta$. The balance between pro- and anti-inflammatory mediators modulates the inflammatory response to AP (32). The presence of IL-10, which is a major anti-inflammatory mediator in AP, diminishes pancreatic damage (27). Therefore, further research into treatments that can modulate various inflammatory mediators may provide a novel method of treating AP. Previous studies determined the anti-inflammatory role of CGRP: CGRP reduces the expression of IL-6, TNF- $\alpha$ and IL- 8 by inhibiting stimulation of nuclear factor- $\kappa \mathrm{B}$ (33) butupregulates the anti-inflammatory mediator IL-10 (34). The present study confirmed that rutaecarpine increases serum concentrations of IL-10 but reduces IL-6 and TNF- $\alpha$ levels by stimulating the release of CGRP. This effect was dose-dependent and was abolished by capsazepine. 
Notably, although the rats in the AP group had not been treated with rutaecarpine prior to surgery, serum IL-10 concentrations increased slightly. This may be due to the protective effect against acute inflammation exhibited by living organisms.

In conclusion, the results of the present study indicate that rutaecarpine protects against injuries caused by AP in rats and that these effects are mediated by the release of CGRP via activation of VR1. Rutaecarpine induces an anti-inflammatory response in the treatment of AP. The results of the present study provide novel insights into the pharmacological therapy of AP.

\section{Acknowledgements}

The present study was supported by the National Natural Science Foundation of China (grant no. 81670589), the Project Sponsored by the Scientific Research Foundation for the Returned Overseas Chinese Scholars, State Education Ministry [grant no. (2015) 311] and the Project from Science and Technology Department, Hunan, China (grant no. 2015SF2020-3).

\section{References}

1. Maksimow M, Kyhälä L, Nieminen A, Kylänpää L, Aalto K, Elima K, Mentula P, Lehti M, Puolakkainen P, Yegutkin GG, et al: Early prediction of persistent organ failure by soluble CD73 in patients with acute pancreatitis". Crit Care Med 42: 2556-2564, 2014.

2. Yadav D and Lowenfels AB: The epidemiology of pancreatitis and pancreatic cancer. Gastrenterology 144: 1252-1261, 2013.

3. Yang ZW, Meng XX and Xu P: Central role of neutrophil in the pathogenesis of severe acute pancreatitis. J Cell Mol Med 19: 2513-2520, 2015.

4. Dellinger EP, Forsmark CE, Layer P, Lévy P, Maraví-Poma E, Petrov MS, Shimosegawa T, Siriwardena AK, Uomo G Whitcomb DC, et al: Determinant-based classification of acute pancreatitis severity: An international multidisciplinary consultation. Ann Surg 256: 875-880, 2012.

5. Forsmark CE and Toskes PP: Acute pancreatitis. Medical management. Crit Care Clin 11: 295-309, 1995.

6. Zhang XP, Li ZJ and Zhang J: Inflammatory mediators and microcirculatory disturbance in acute pancreatitis. Hepatobiliary Pancreat Dis Int 8: 351-357, 2009.

7. Klar E, Schratt W, Foitzik T, Buhr H, Herfarth C and Messmer K: Impact of microcirculatory flow pattern changes on the development of acute edematous and necrotizing pancreatitis in rabbit pancreas. Dig Dis Sci 39: 2639-2644, 1994.

8. Zhou ZG and Chen YD: Influencing factors of pancreatic microcirculatory impairment in acute panceatitis. World J Gastroenterol 8: 406-412, 2002.

9. Gómez-Cambronero LG, Sabater L, Pereda J, Cassinello N, Camps B, Viña J and Sastre J: Role of cytokines and oxidative stress in the pathophysiology of acute pancreatitis: Therapeutical implications. Curr Drug Targets Inflamm Allergy 1: 393-403, 2002.

10. Xiang H, Zhang Q, Qi B, Tao X, Xia S, Song H, Qu J and Shang D: Chinese herbal medicines attenuate acute pancreatitis: Pharmacological activities and mechanisms. Front Pharmacol 8: 216, 2017.

11. Wang L, Hu CP, Deng PY, Shen SS, Zhu HQ, Ding JS, Tan GS and $\mathrm{Li}$ YJ: The protective effects of rutaecarpine on gastric mucosa injury in rats. Planta Med 71: 416-419, 2005.

12. Lee SH, Son JK, Jeong BS, Jeong TC, Chang HW, Lee ES and Jahng Y: Progress in the studies on rutaecarpine. Molecules 13: 272-300, 2008.

13. Yu J, Tan GS, Deng PY, Xu KP, Hu CP and Li YJ: Involvement of CGRP in the inhibitory effect of rutaecarpine on vasoconstriction induced by anaphylaxis in guinea pig. Regul Pept 125: 93-97, 2005.
14. Li JZ, Peng J, Xiao L, Zhang YS, Liao MC, Li XH, Hu CP, Deng HW and Li YJ: Reversal of isoprenaline-induced cardiac remodeling by rutaecarpine via stimulation of calcitonin gene-related peptide production. Can J Physiol Pharmacol 88: 949-959, 2010.

15. Deng PY, Ye F, Cai WJ, Tan GS, Hu CP, Deng HW and Li YJ: Stimulation of calcitonin gene-related peptide synthesis and release: Mechanisms for a novel antihypertensive drug, rutaecarpine. J Hypertens 22: 1819-1829, 2004.

16. Peng J and Li YJ: The vanilloid receptor TRPV1: Role in cardiovascular and gastrointestinal protection. Eur J Pharmacol 627: $1-7,2010$

17. Warzecha Z, Dembiński A, Jaworek J, Ceranowicz P, Szlachcic A, Walocha J and Konturek SJ: Role of sensory nerves in pancreatic secretion and caerulein-induced pancreatitis. J PhysiolPharmacol 48: 43-58, 1997.

18. Warzecha Z, Dembiński A, Ceranowicz P, Konturek PC, Stachura J, Konturek SJ and Niemiec J: Protective effect of calcitonin gene-related peptide against caerulein-induced pancreatitis in rats. J Physiol Pharmacol 48: 775-787, 1997.

19. Dembiński A, Warzecha Z, Ceranowicz P, Jaworek J, Sendur R, Knafel A, Dembiński M, Bilski J, Pawlik WW, Tomaszewska R, et al: Stimulation of sensory nerves and CGRP attenuate pancreatic damage in ischemia/reperfusion induced pancreatitis. Med Sci Monit 9: BR418-BR425, 2003.

20. Van den Worm E, de Vires A, Nijkamp FP and Engels F: Capsazepine, a vanilloid receptor antagonist, inhibits allergen-induced tracheal contraction. Eur J Pharmacol 518: 77-78, 2005.

21. Huan G, Jie P and Jixiang M: Experimental study of therapeutic use of rutecarpin in severe acute pancreatitis. Chin J Gen Surg 23, 2014.

22. Hu CP, Xiao L, Deng HW and Li YJ: The cardioprotection of rutaecarpine is mediated by endogenous calcitonin related-gene peptide through activation of vanilloid receptors in guinea-pig hearts. Planta Med 68: 705-709, 2002.

23. Sternini C, De Giorgio R and Furness JB: Calcitonin gene-related peptide neurons innervating the canine digestive system. Regul Pept 42: 15-26, 1992.

24. National Research Council (US) Institute for Laboratory Animal Research: Guide for the Care and Use of Laboratory Animals. National Academies Press (US), Washington, DC, 1996. http://oacu.od.nih.gov/regs/guide/guide.pdf.

25. Aho HJ and Nevalainen TJ: Experimental pancreatitis in the rat. Ultrastructure of sodium taurocholate-induced pancreatic lesions. Scand J Gastroenterol 15: 417-424, 1980.

26. Yilmaz M, Topsakal S, Herek O, Ozmen O, Sahinduran S, Buyukoglu T and Yonetci N: Effects of etanercept on sodium taurocholate-induced acute pancreatitis in rats. Transl Res 154: 241-249, 2009.

27. Keceli M, Kucuk C, Sozuer E, Kerek M, Ince O and Arar M: The effect of interleukin-10 on acute pancreatitis induced by cerulein in a rat experimental model. J Invest Surg 18: 7-12, 2005.

28. Menger MD, Plusczyk T and Vollmar B: Microcirculatory derangements in acute pancreatitis. J Hepatobiliary Pancreat Surg 8: 187-194, 2001.

29. Hu CP, Xiao L, Deng HW and Li YJ: The depressor and vasodilator effects of rutaecarpine are mediated by calcitonin gene-related peptide. Planta Med 69: 125-129, 2003.

30. Caterina MJ and Julius D: The vanilloid receptor: A molecular gateway to the pain pathway. Annu Rev Neurosci 24: 487-517, 2001.

31. Wimalawansa SJ: Calcitonin gene-related peptide and its receptors: Molecular genetics, physiology, pathophysiology, and therapeutic potentials. Endocr Rev 17: 533-585, 1996.

32. Pérez S, Pereda J, Sabater L and Sastre J: Redox signaling in acute pancreatitis. Redox Biol 5: 1-14, 2015.

33. Monneret G, Pachot A, Laroche B, Picollet J and Bienvenu J: Procalcitonin and calcitonin gene-related peptide decrease LPS-induced tnf production by human circulating blood cells. Cytokine 12: 762-764, 2000.

34. Granger J and Remick D: Acute pancreatitis: Models, markers, and mediators. Shock 24 (Suppl 1): S45-S51, 2005. 